\title{
ADOPT: A Historically Validated Light Duty Vehicle Consumer Choice Model
}

\section{Aaron Brooker, Jeffrey Gonder, and Sean Lopp}

National Renewable Energy Laboratory

\section{Jacob Ward}

Department of Energy

CITATION: Brooker, A., Gonder, J., Lopp, S., and Ward, J., "ADOPT: A Historically Validated Light Duty Vehicle Consumer Choice Model," SAE Technical Paper 2015-01-0974, 2015, doi:10.4271/2015-01-0974.

Copyright (C) 2015 SAE International

\begin{abstract}
The Automotive Deployment Options Projection Tool (ADOPT) is a light-duty vehicle consumer choice and stock model supported by the U.S. Department of Energy's Vehicle Technologies Office. It estimates technology improvement impacts on future U.S. light-duty vehicles sales, petroleum use, and greenhouse gas emissions.
\end{abstract}

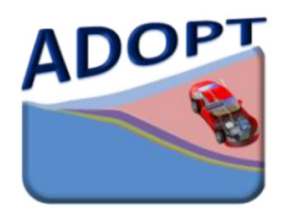

ADOPT uses techniques from the multinomial logit method and the mixed logit method to estimate vehicle sales. Specifically, it estimate sales based on the weighted value of key attributes including vehicle price, fuel cost, acceleration, range and usable volume. The average importance of several attributes changes nonlinearly across its range and changes with income. For several attributes, a distribution of importance around the average value is used to represent consumer heterogeneity. The majority of existing vehicle makes, models, and trims are included to fully represent the market. The Corporate Average Fuel Economy regulations are enforced.

The sales feed into the ADOPT stock model. It captures key aspects for summing petroleum use and greenhouse gas emissions. This includes capturing the change in vehicle miles traveled by vehicle age, the creation of new model options based on the success of existing vehicles, new vehicle option introduction rate limits, and survival rates by vehicle age.

ADOPT has been extensively validated with historical sales data. It matches in key dimensions including sales by fuel economy, acceleration, price, vehicle size class, and powertrain across multiple years.
A graphical user interface provides easy and efficient use. It manages the inputs, simulation, and results.

\section{Introduction}

The Automotive Deployment Options Projection Tool (ADOPT) was created to estimate the impact of vehicle technology improvements on petroleum use and greenhouse gas (GHG) emissions with a reasonable level of confidence. In the past, many models estimated far more hybrid electric vehicle (HEV) sales than were actually sold [1]. ADOPT was developed to ground future estimates in reality by matching historical sales, matching for the right reasons, and capturing key future influences.

\section{Approach}

While consumers may consider many different vehicle attributes when deciding to purchase a new vehicle, ADOPT assumes that their ultimate decision is primarily driven by a much smaller subset of key factors. The framework varies the importance of these attributes by income to account for the greater sensitivity to cost at lower levels of income, the higher rates of purchase at higher incomes, and the changing level of income over time. Their importance was set to match historical sales. Most of the existing vehicle options were included to enable extensive validation and provide a complete representation of the market. ADOPT's stock model uses the sales to estimate fuel use and GHG emissions. It captures key aspects, including the changing vehicle miles traveled (VMT) as vehicles age, new model option creation, and scrap rates. A simple graphical user interface (GUI) provides access to most inputs and assumptions used by the model, manages scenario setups, and displays results.

\section{Inputs}

There are five key time-based inputs to ADOPT:

- Technology improvements

- New vehicle attributes 
- Fuel prices

- Income distribution

- Fueling station availability.

The time-based technology improvement options include:

- $\quad$ Battery price

- Motor price

- $\quad$ Spark ignition engine efficiency

- Compression ignition engine efficiency

- Atkinson cycle engine efficiency

- $\quad$ Lightweighting.

The improvements over time are applied to all the vehicles in the database. High-level equations, or the embedded Future Automotive Systems Technology Simulator (FASTSim) [2], are used to approximate the impact that they have on the vehicle attributes. For example, as lightweighting increases, the efficiency and fuel cost are adjusted as described in []ㅡ.

The fuel price data in ADOPT are from the Energy Information Administration's Annual Energy Outlook [4]].

The income distribution is from the U.S. Census Bureau []․ As seen in Figure 1, the historical trend for each of the income bins is relatively linear. Therefore, the default input in ADOPT extrapolates the trends into the future, as seen by the dotted lines.

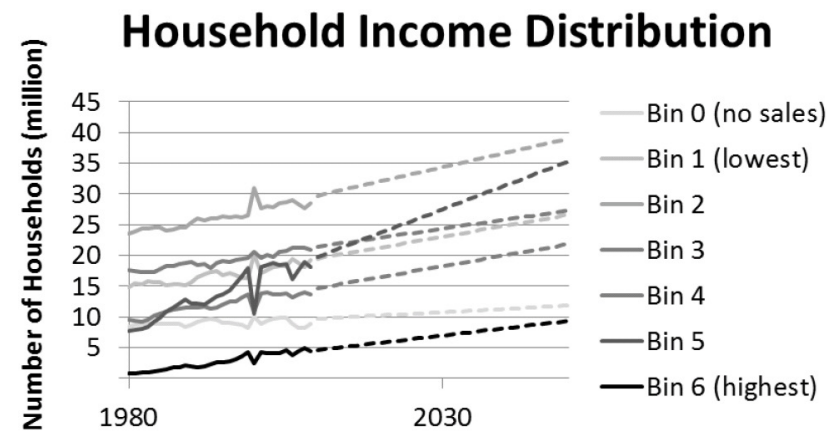

Figure 1. Household income trends in 2013 Consumer Price Index using Current Methods-adjusted dollars

The fueling station availability input is defined by three metrics:

- $\quad$ Long distance miles

- Average miles to a station

- Number of stations in a region.

These metrics reflect trends found in a study that evaluated refueling station availability impact on consumer preference [] $]$. The study was conducted three times, each time improving the approach and results.

\section{Consumer Choice}

Consumer choice is modeled using concepts from the standard multinomial logit and mixed multinomial logit methods. The standard logit method estimates sales based on the weighted value of the vehicle attributes. The mixed logit method uses a distribution of weighting coefficients to capture consumer preference heterogeneity.
A variation of the standard multinomial logit method is used, as shown in Equation 1.

$$
S_{V}=\frac{E X P\left(\sum_{A}\left(E_{A} \times V_{A}\right)\right)^{x}}{\sum_{V}\left(\operatorname{EXP}\left(\sum_{A}\left(E_{A} \times V_{A}\right)\right)^{x}\right)}
$$

Where:

- $\mathrm{S}_{\mathrm{V}}$ : Market share for vehicle model V

- $\mathrm{E}_{\mathrm{A}}$ : Coefficient for attribute A

- $\mathrm{V}_{\mathrm{A}}$ : Value of attribute $\mathrm{A}$ for vehicle $\mathrm{V}$

- $\quad \mathrm{x}$ : Sales distribution factor

The sales distribution factor was added to the standard logit method to improve the grouping of sales. Using the standard logit method, the distribution of high- and low-selling vehicle models did not match historical sales. Specifically, the model estimated sales that were more evenly distributed across vehicle models than actually occurred. The sales distribution factor pushed more vehicle models to have sales above the 300,000 per year level, and matched the actual distribution better, as seen in Figure 2

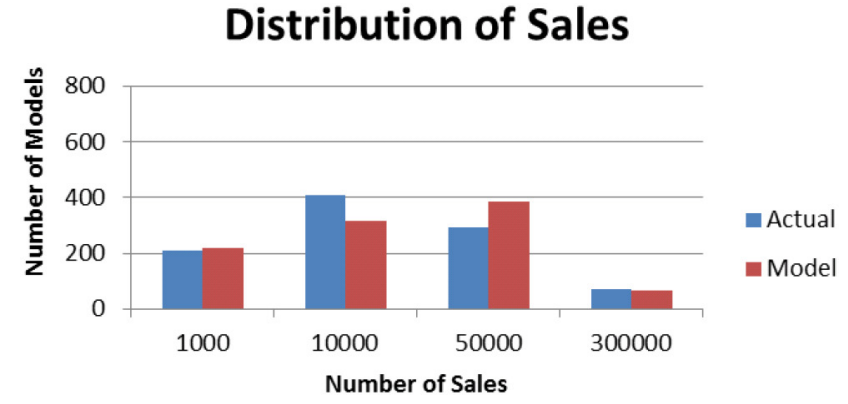

Figure 2. Distribution of sales

The attribute coefficients used in the logit method are non-linear and vary with income, as seen in Figure 3 . The y-axis shows the price equivalent value by characteristic, which represents the equivalent amount of change in price that a change in attribute has. The $\mathrm{x}$-axis shows the value of the attribute as a percentage, with $0 \%$ representing the lowest value within the range of that attribute. For example, the fastest accelerating vehicle goes from 0 to 60 miles per hour (MPH) in 3.9 seconds, which is represented as $0 \%$, and for the $\$ 133,000$ income bin effectively increases the perceived value by $\$ 20,000$ compared to the average acceleration.

\section{MSRP Equivalent Value by Characteristic}

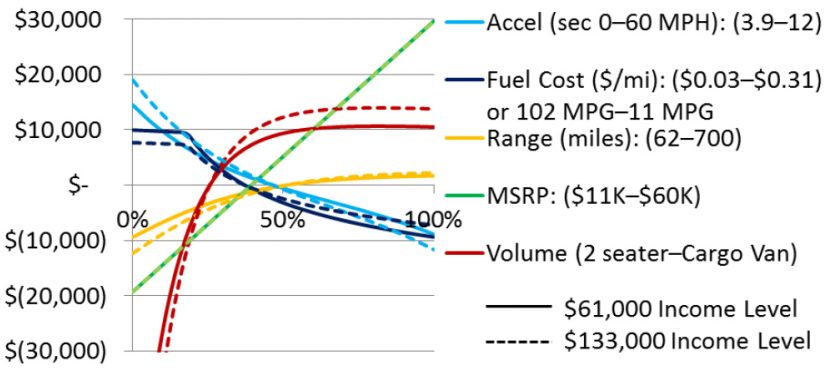

Figure 3. Attribute coefficient variations 
For several attributes, their change in value is non-linear over their range. Specifically, the values of acceleration, fuel cost, vehicle range, and volume change non-linearly. For example, as seen in $\underline{\text { Figure } 3}$, the slope of the volume attribute becomes steeper as the vehicle gets smaller and loses seating and cargo capacity.

The value of vehicle attributes also changes with income, as seen in Figure 3 by comparing the dotted lines to the solid lines. For example, better acceleration is more important to higher income households, represented by a larger change in equivalent MSRP. Or conversely, lower income households place greater value on price and fuel cost compared to high income households.

ADOPT also captures variations in consumer preference using a technique similar to the mixed logit method. It uses a normal distribution around each attribute curve to approximate variations in consumer taste. Different combinations of coefficients values are then sampled from the distributions to create a wide variety of consumer preferences.

A distribution of preferences improves substitution patterns as new vehicle models are added. The standard logit method generally violates an axiom of decision theory called the independence of irrelevant alternatives. As an example of what problem this theory highlights, assume there are a car and a truck of equal preference and thus sales. If another car identical to the original is added to the option set, a model should estimate the same total sales of cars and trucks because there is no relevant change in options. The same total car sales should be split between the two cars. The standard logit method, however, will estimate that all three vehicles have equal sales because it estimates a distribution of sales based on one set of equal preferences. A distribution of preferences, however, reduces this tendency because the majority of those who purchased the truck have a different set of preferences than those who purchased the car, and will thus continue to purchase the truck.

\section{Vehicle Dataset}

The consumer choice model is applied to the majority of the existing light-duty vehicle options to estimate sales. This includes most makes, models, and trims that have different engine sizes. It was created from several sources including www.carsdirect.com, the U.S. Environmental Protection Agency [7], and Polk. The 2014 database includes over 400 different options.

Including most existing vehicle options has several key benefits. One, it captures a diversity of vehicles. Historical sales have shown that a diversity of vehicles is key to accurately estimating sales. For example, if a limited dataset is used that assumes a single HEV that has similar performance to an average conventional vehicle (CV), it would miss the Toyota Prius with its relatively slow acceleration $[\underline{8}, \underline{9}, \underline{10}]$, and the Prius accounts for half of HEV sales [11]. Furthermore, the bestselling HEV that has performance similar to its conventional counterpart averages one-third as many sales [11], and some lower-selling options are no longer on the market. To capture high-selling vehicles that have outlier attributes, like the Prius, a large diversity of vehicles must be considered.
Two, including most vehicle makes and models is important for validation. It provides the ability for ADOPT to be validated in many dimensions, at aggregate and individual vehicle levels, and over time.

Three, a large vehicle dataset reduces multicollinearity when calibrating, where two or more predictor variables in a multiple regression model are highly correlated. In the past, when all the vehicle options were CVs, adding more vehicles did not help separate the importance of certain attributes. For example, adding vehicles with different engine sizes did not isolate the importance of fuel economy, cost, and better acceleration because they all correlated with engine size. With the introduction of a variety of powertrains, including HEVs, plug-in HEVs, and all-electric vehicles, these correlations no longer hold true. For example, contrary to CVs, HEVs tend to have higher cost and higher fuel economy. They also have different trade-offs with acceleration and fuel economy. Capturing these variations allowed for the creation and validation of the non-linear importance of the different attributes over their range shown in Figure 3.

A fourth benefit to a full vehicle dataset is capturing Corporate Average Fuel Economy (CAFE) impacts. CAFE is a key driver of vehicle sales because vehicle efficiency follows CAFE regulations, as seen in Figure 4. Because CAFE is based on vehicle footprint, it has different implications for each vehicle. For example, the 2015 Smart ForTwo achieves a U.S. Environmental Protection Agency adjusted fuel economy of 36 MPG [12]. While small efficient vehicles like this previous helped manufacturers conform to CAFE regulations, the new footprint-based rules would require it to significantly improve to an U.S. Environmental Protection Agency adjusted fuel economy above 45 MPG in 2025 [13] for it to help.

\section{CAFE and New Car Fuel Economy}

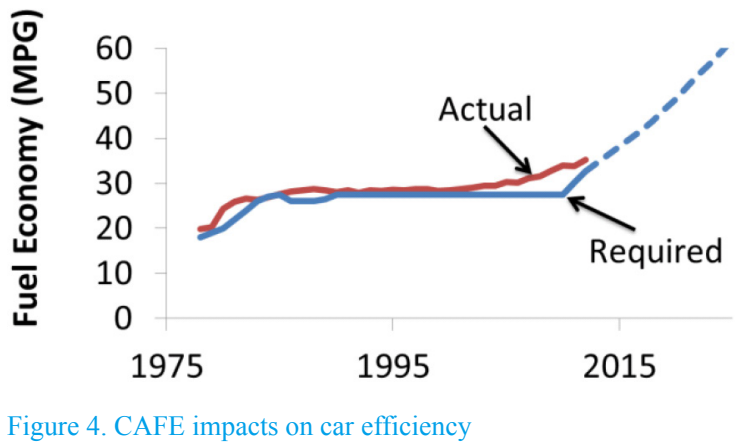

\section{CAFE}

ADOPT drives sales to conform to future CAFE regulations by applying three techniques similar to those used in the past. As seen in Figure 5, fuel economy started ramping up in 1978 with the CAFE regulation. During that time, the vehicle power went down and slowed vehicle acceleration. Reducing the engine power improved vehicle efficiency because smaller engines tend to operate more efficiently. ADOPT reflects this trend by reducing engine power when the fraction of vehicle options meeting CAFE fall below a specified level. The amount of engine downsizing is limited to another specified level. High-level equations, or the embedded vehicle model FASTSim [2] , are used to estimate the downsizing impact on efficiency, acceleration, and price. 


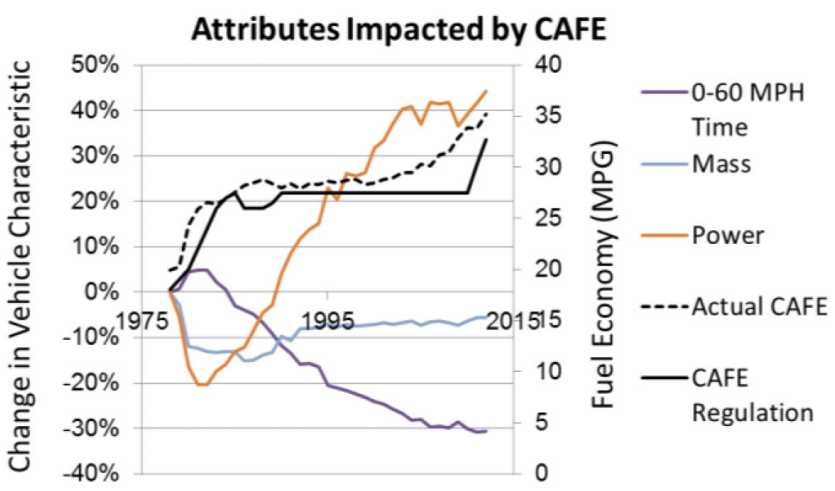

Figure 5. Changes in vehicle attributes as CAFE ramped up

The second technique ADOPT uses to conform to CAFE is through vehicle technology improvements over time. As seen in Figure 5, after the initial drop, the power and acceleration improved over time, even beyond the initial levels, while CAFE was maintained. ADOPT captures this trend by allowing inputs for technology improvements over time. As noted, the technology improvements include:

- $\quad$ Battery cost reductions

- Motor cost reductions

- Engine efficiency improvements

- $\quad$ Lightweighting.

The third technique ADOPT uses to conform to CAFE are incentives and penalties. Vehicle price incentives are applied to vehicles exceeding CAFE proportional to the amount they exceed it. Similarly, price penalties are applied to vehicles falling short of CAFE proportional to the shortfall. The model iterates to find incentive and penalty rates that when applied offset each other.

\section{Stock Model}

ADOPT's stock model captures key aspects for estimating the fuel use and GHG emissions based on the estimated sales. It captures the change in VMT per year with vehicle age, creation of new model options, the maximum ramp up in sales of new model options, and nonlinear survival rates.

\section{Vehicle Miles Traveled}

\section{Vehicle Travel by Age}

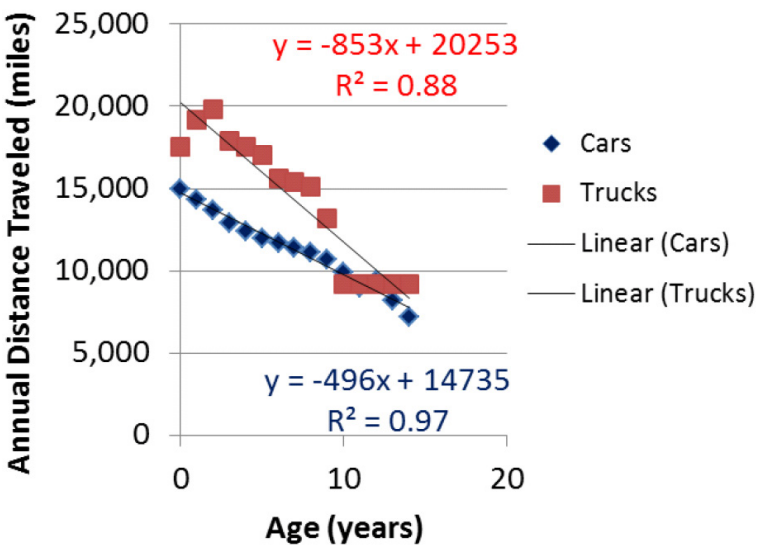

Figure 6. VMT by vehicle age

ADOPT captures the trend of VMT changing with vehicle age, as shown in Figure 6. This is important because new vehicles typically travel twice the distance of older vehicles [14]. Therefore, if efficient vehicle sales increase, ADOPT captures the much faster and larger impact than would be captured assuming a constant VMT.

\section{New Model Options}

ADOPT introduces new model options based on several trends. To approximate new model options for a new powertrain, a single new option must be added to the input vehicle dataset for a specified year. ADOPT then uses a Bass Diffusion s-function to estimate the number of additional model options with that powertrain introduced over several subsequent years set to match past trends, as seen in Figure 7.

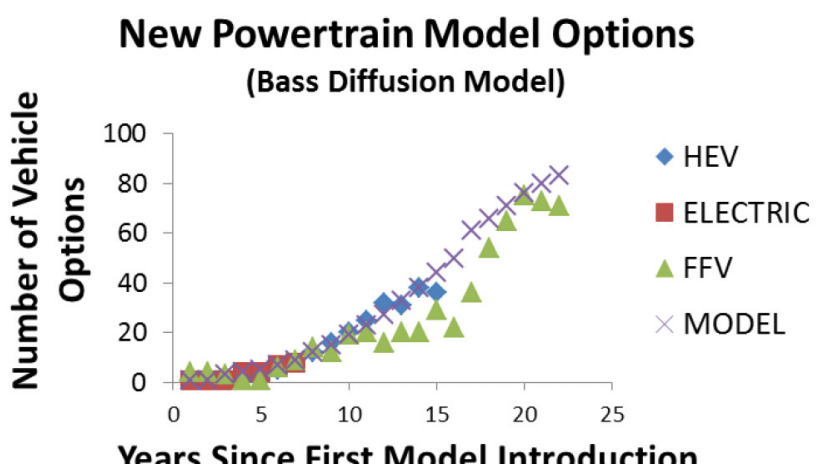

Figure 7. Bass Diffusion curve that estimates the cumulative number of vehicle options for a new powertrain

Variations in the new model options are created by copying the bestselling CVs and swapping out their powertrains with the new one. Then, the powertrain component sizes are randomly modified to provide a variety of options in the market. This approach mirrors the wide variety in performance, efficiency, and size of HEV options historically introduced.

After several introductory years, additional model options are introduced if sales exceed typical levels for a given vehicle price, as seen in Figure 8. The new model option trigger curve is fit just above typical current levels of sales for different price points, as shown by the points in the chart. The curve is applied to all existing vehicle options.

\section{New Model Trigger}

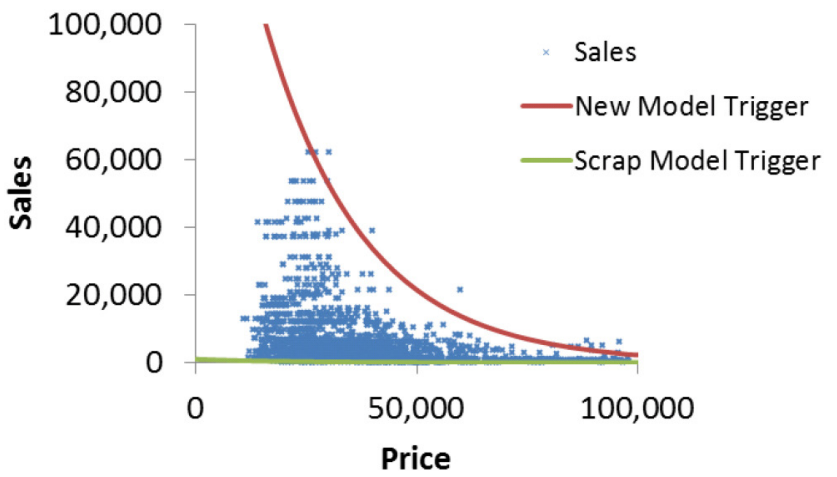

Figure 8 . The price vs. sales curve that triggers a new vehicle model option

Similar to the new model option trigger, vehicle options selling below a threshold for their price, the scrap model trigger, are eliminated from the dataset.

The stock model limits the rate that new vehicle model option sales can increase, as seen in Figure 9. It uses a power fit limit based on initial sales of the bestselling HEV, the Prius. Figure 9 also shows other high-selling advanced powertrains, and they support this trend [11]. 


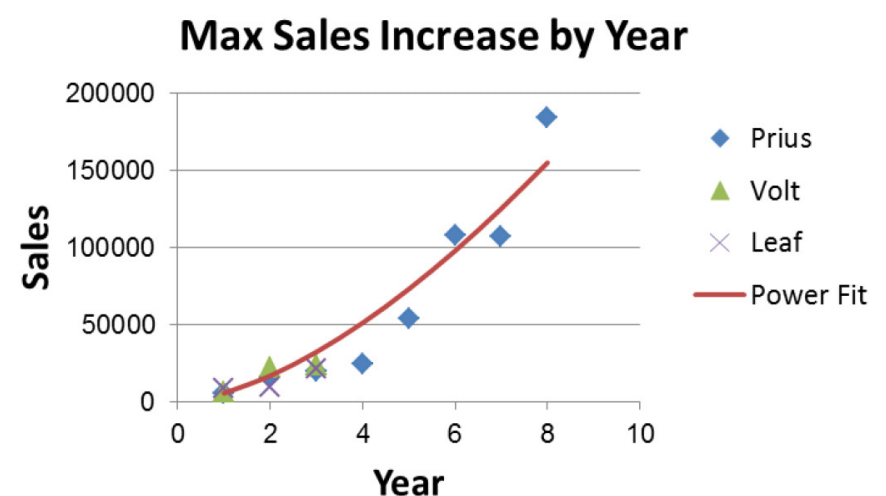

Figure 9. Imposed sales increase limits of new vehicle model options

\section{Survival Rates}

Survival rates in ADOPT are a function of vehicle age. They are non-linear and based on trends from the Transportation Energy Data Book [14], as seen in Figure 10. These curves are modified by year to capture the increasing median vehicle age, which has increased over $50 \%$ since $1970[\underline{14}, \underline{15}]$. These trends are key for accurate fuel use estimates.

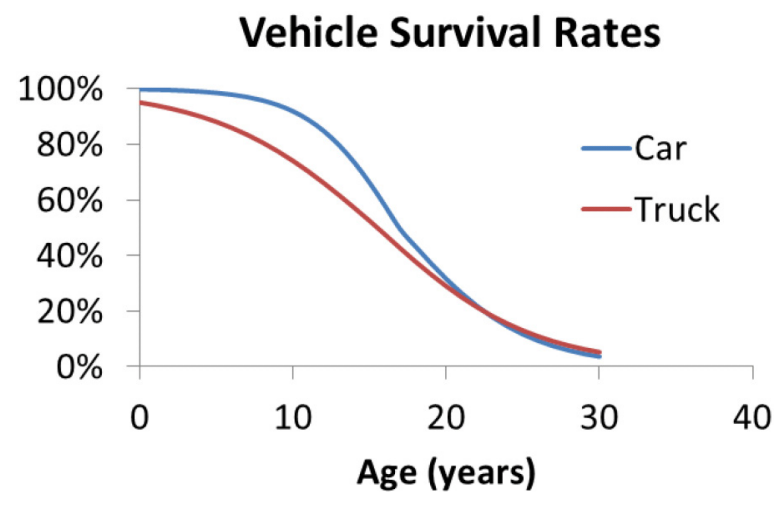

Figure 10. Vehicle survival rates by age

\section{Validation}

ADOPT validates well in key dimensions for estimating petroleum use and GHG emissions. To validate the model, the attribute importance curves were calibrated for one year, as shown in Figure 3, and then held constant for all other sales estimates. Because the focus is on aggregate petroleum use and GHG emissions, most of the validation compares the aggregate model sales estimates to actual sales for relevant key metrics, years, and regions.

The constant term, or calibration constant, generally required by the logit method to match historical sales, is not used for validation except when comparing specific trim levels over time. This ensures that the attribute weightings accurately estimate the key aggregated metrics. While this may cause ADOPT to inaccurately distribute sales among very similar vehicle trims, the key aggregate results still match.

ADOPT attribute weightings were calibrated to U.S. sales in 2012. As seen in Figure 11, Figure 12, Figure 13, Figure 14, Figure 15, sales match well by powertrain, fuel economy, acceleration, vehicle price, and vehicle size class.
Percent HEV

Sales

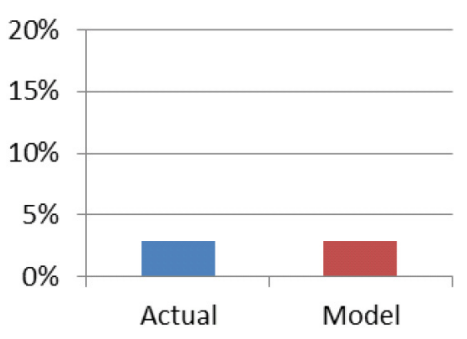

Figure 11. Sales calibration by vehicle powertrain in 2012

\section{Sales By Fuel Economy (listed by max in bin)}

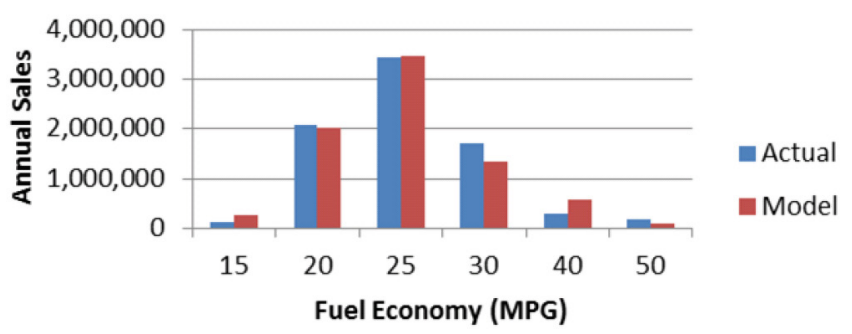

Figure 12. Sales calibration by vehicle fuel economy in 2012

\section{Sales By Acceleration}

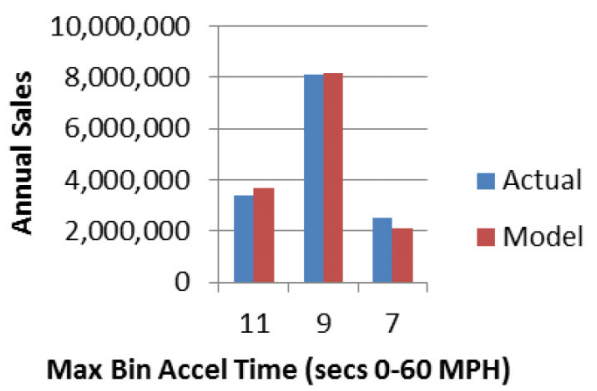

Figure 13. 2012 Sales calibration by vehicle acceleration in 2012

\section{Sales By MSRP (listed by max in bin)}

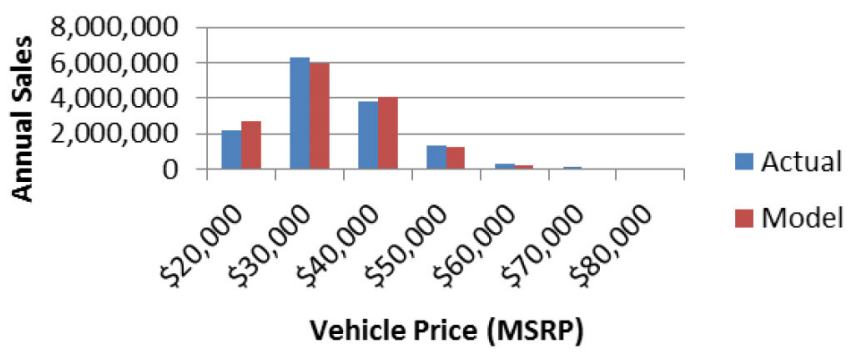

Figure 14. Sales calibration by manufacturer's suggested retail price (MSRP) in 2012 


\section{Sales By Class}

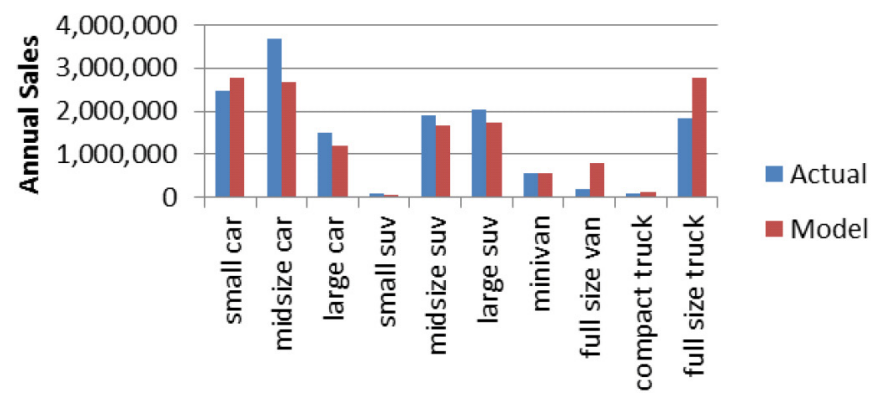

Figure 15. Sales calibration by vehicle size class in 2012

Additional comparisons were made for other years to ensure the model matched for different fuel prices and income levels. One of the additional validation comparisons used U.S. sales data from 2008, as shown in Figure 16, Figure 17, Figure 18, Figure 19, Figure 20, which had very different economic conditions than the calibration year.

\section{Percent HEV}

\section{Sales}

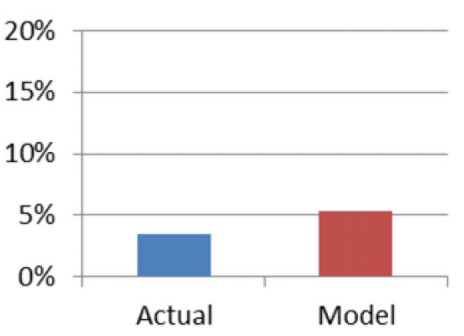

Figure 16. U.S. sales validation by vehicle powertrain for 2008

Sales By Fuel Economy (listed by max in bin)

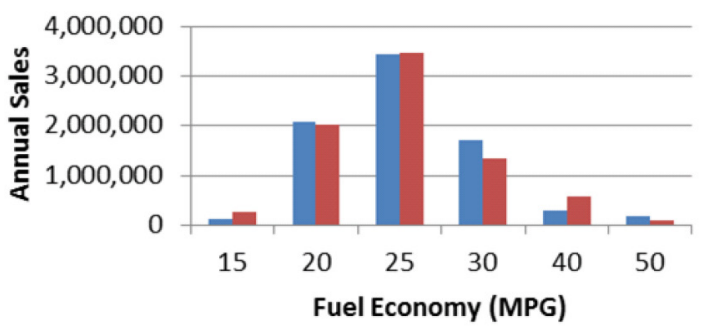

Figure 17. U.S. sales validation by fuel economy in 2008

\section{Sales By Acceleration}

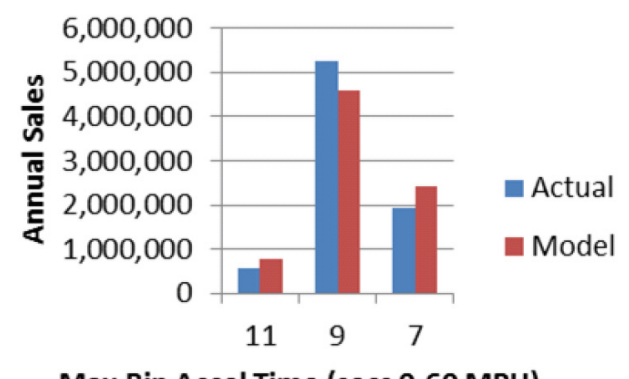

Max Bin Accel Time (secs 0-60 MPH)

Figure 18. U.S. sales validation by acceleration in 2008

\section{Sales By MSRP}

(listed by max in bin)

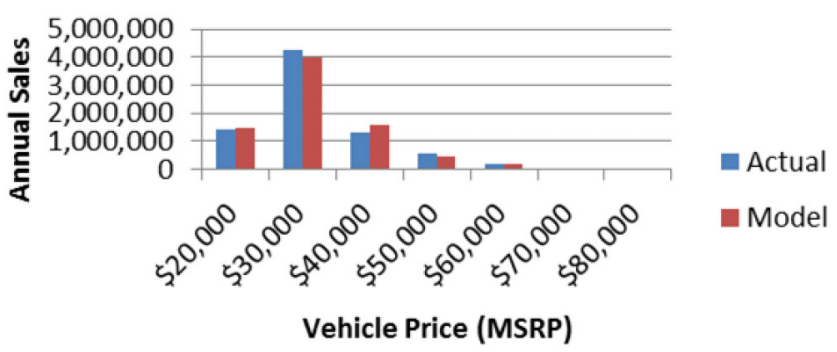

Figure 19. U.S. sales validation by MSRP in 2008

\section{Sales By Class}

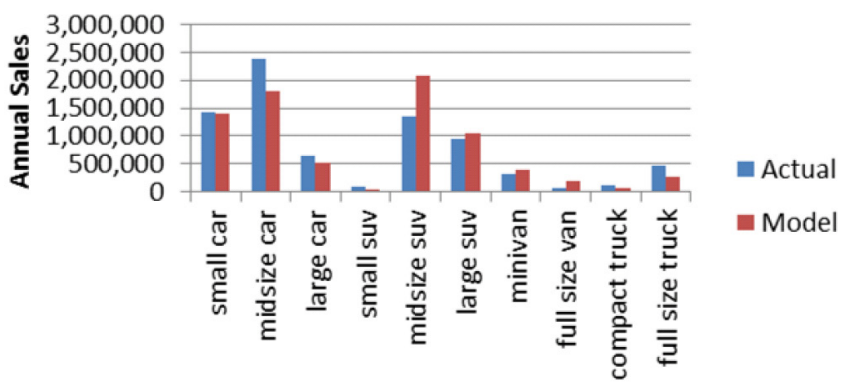

Figure 20. U.S. sales validation by size class in 2008

To further validate the impacts of income on attribute importance, ADOPT's results were compared to actual sales for many different distributions of income and fuel prices by simulating different ZIP Codes. Two examples, one from St. Louis, Missouri, and one from Arvada, Colorado, are shown in Figure 21, Figure 22, Figure 23, Figure 24, Figure 25, Figure 26, Figure 27, Figure 28, Figure 29, Figure 30.

\section{Percent HEV}

Sales

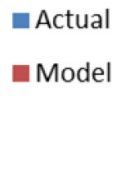

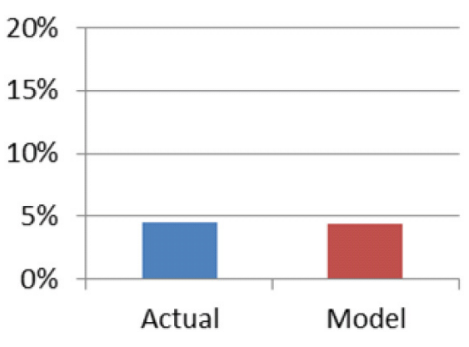

Figure 21. Sales validation by powertrain for ZIP Code 63005 in St. Louis, Missouri, in 2008

\section{Sales By Fuel Economy (listed by max in bin)}

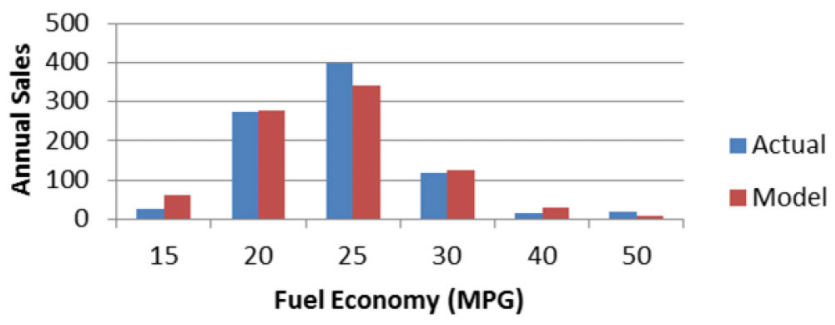

Figure 22. Sales validation by fuel economy for ZIP Code 63005 in St. Louis, Missouri, in 2008 
Sales By Acceleration

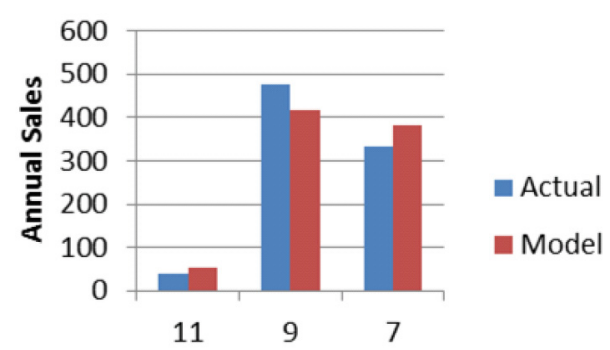

Max Bin Accel Time (secs 0-60 MPH)

Figure 23. Sales validation by acceleration for ZIP Code 63005 in St. Louis, Missouri, in 2008

\section{Sales By MSRP}

(listed by max in bin)

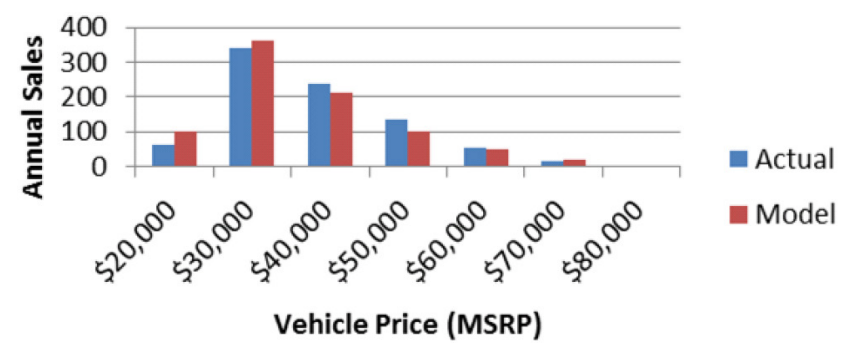

Figure 24. Sales validation by MSRP for ZIP Code 63005 in St. Louis, Missouri, in 2008

\section{Sales By Class}

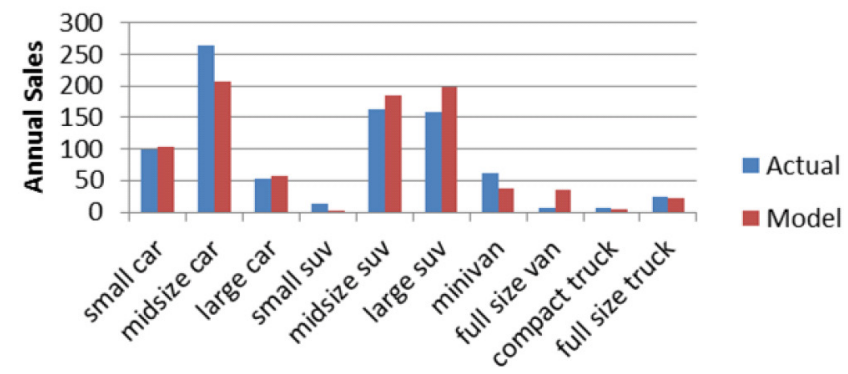

Figure 25. Sales validation by size class for ZIP Code 63005 in St. Louis, Missouri, in 2008

\section{Percent HEV}

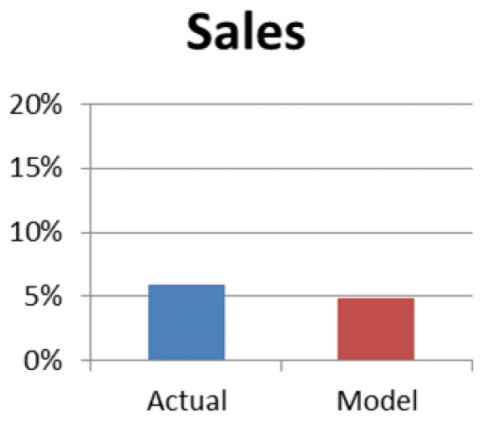

Figure 26. Sales validation by powertrain for ZIP Code 80004, in Arvada, Colorado, in 2008
Sales By Fuel Economy

(listed by max in bin)

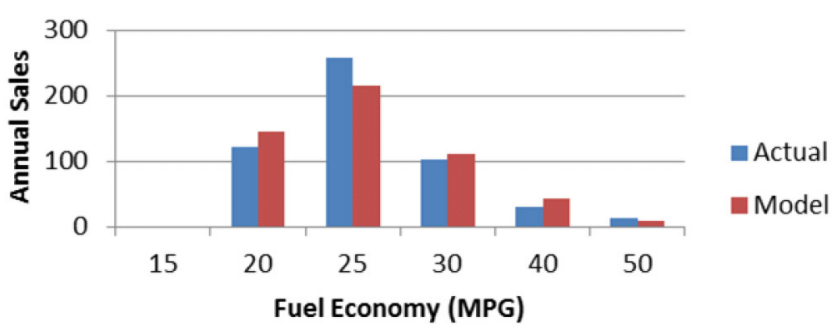

Figure 27. Sales validation by fuel economy for ZIP Code 80004 in Arvada, Colorado, in 2008

\section{Sales By Acceleration}

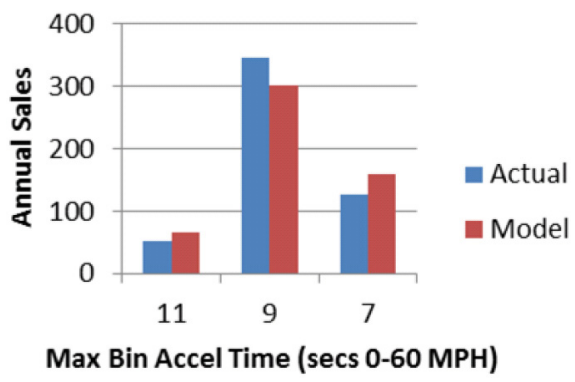

Figure 28. Sales validation by acceleration for ZIP Code 80004 in Arvada, Colorado, in 2008

\section{Sales By MSRP}

(listed by max in bin)

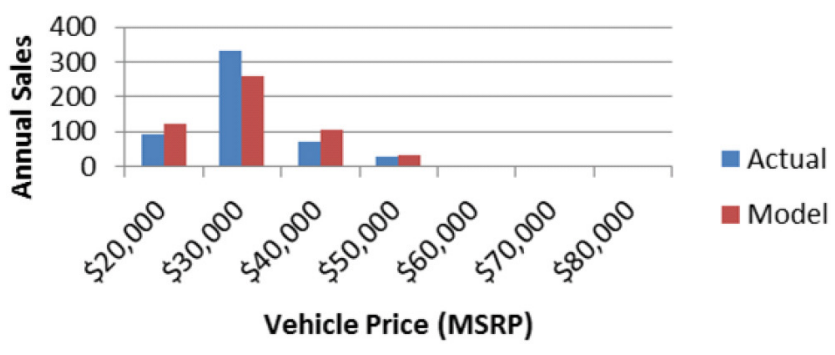

Figure 29. Sales validation by MSRP for ZIP Code 80004 in Arvada, Colorado, in 2008

\section{Sales By Class}

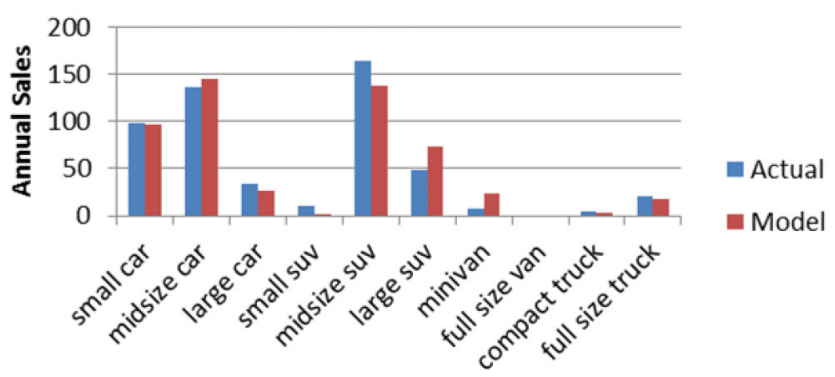

Figure 30. Sales validation by size class for ZIP Code 80004 in Arvada, Colorado, in 2008 
Not only were the level of sales compared to actual data, but who was purchasing the vehicles was also considered. Specifically, ADOPT's estimate of the income of HEV buyers was compared to actual income, as shown in Figure 31.
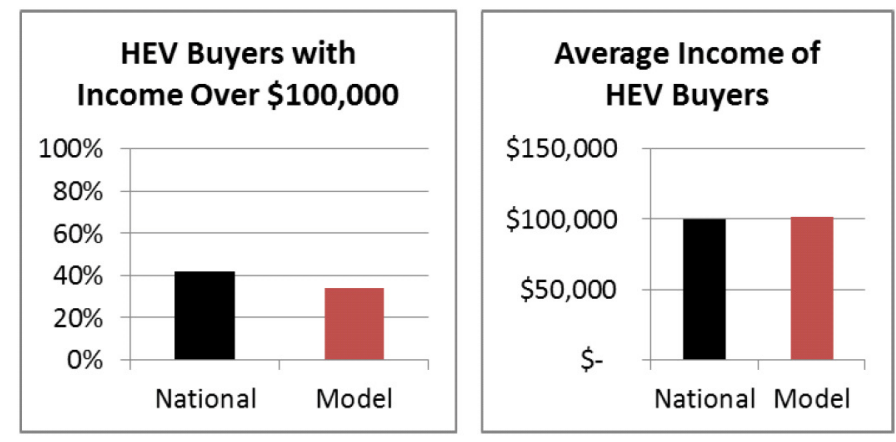

Figure 31. Sales validation for who is purchasing hybrids in the United States

ADOPT results were also compared to sales over time. Figure 32 shows the comparison between ADOPT model estimates and actual sales of HEVs.

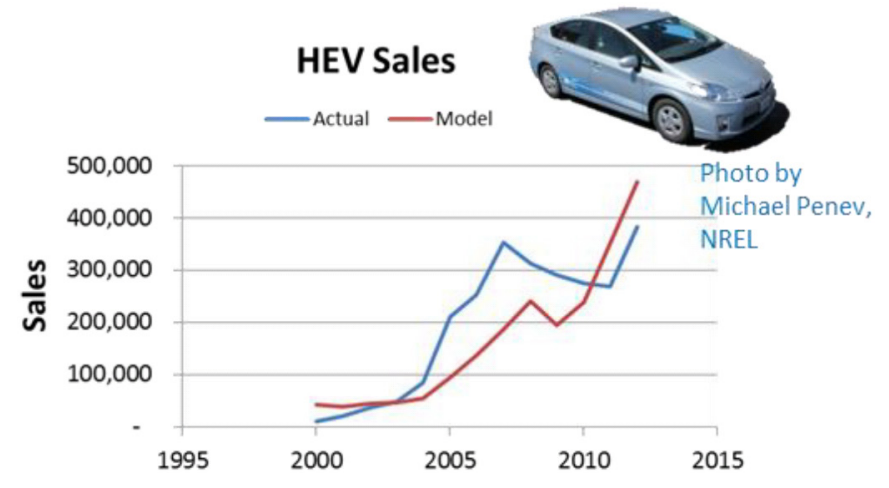

Figure 32. Sales validation for HEVs over time

Figure 33 compares ADOPT's estimate of the number of cars and trucks sold to the actual sold over time.

\section{Car Sales}
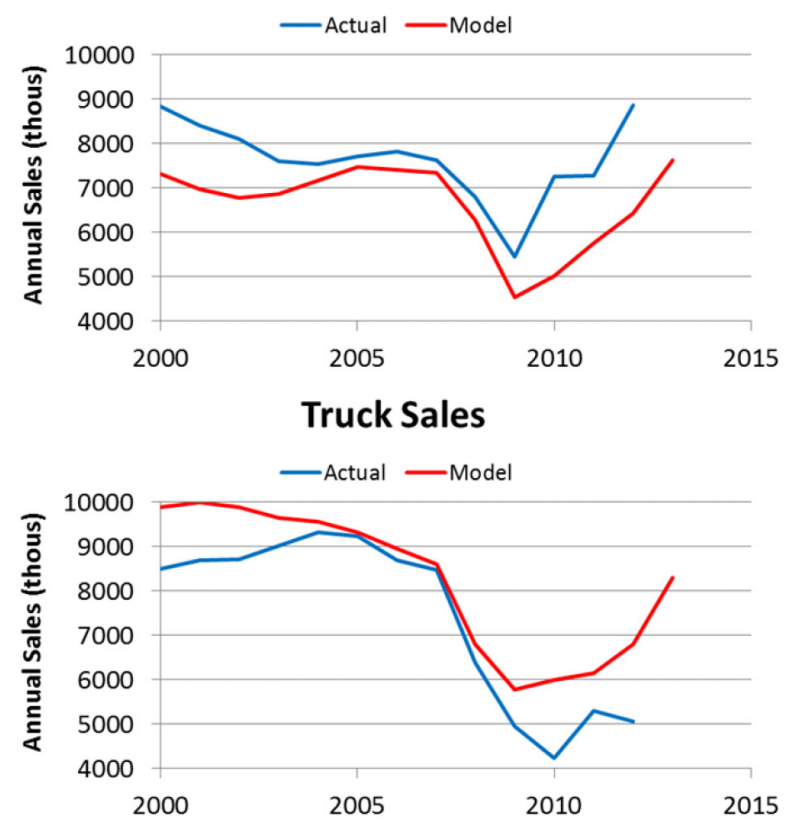

Figure 33. Sales validation of the number of cars and trucks
Unlike aggregate results, a single calibration constant is used for each vehicle trim when validating a specific vehicle trim over time. This captures trim level differences, reliability, or body style, which are not specified in ADOPT. In these cases, the constant term is constrained to have a relatively small influence and is held constant over time. Calibrated constant terms are also used for future sales estimates to ensure proper sales distributions and new model option creation. Figure 34 and Figure 35 show ADOPT's estimate of two high-selling plug-in electric vehicles (Volt and Leaf, respectively) to actual sales using a calibration constant that was calibrated for 2012.

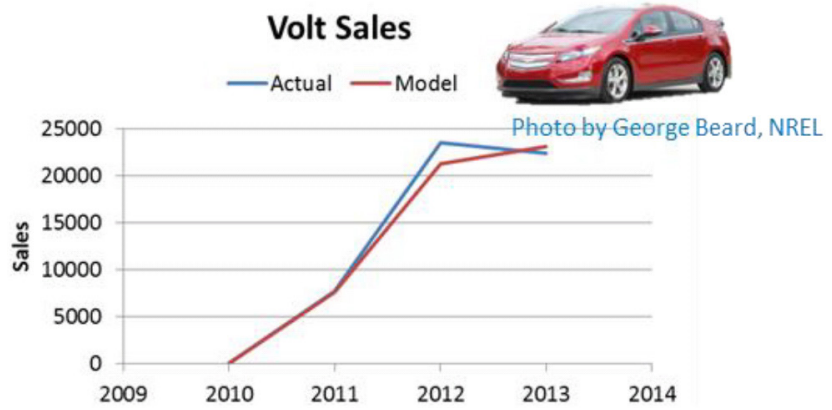

Figure 34. Sales validation for high-selling plug-in electric vehicle over time

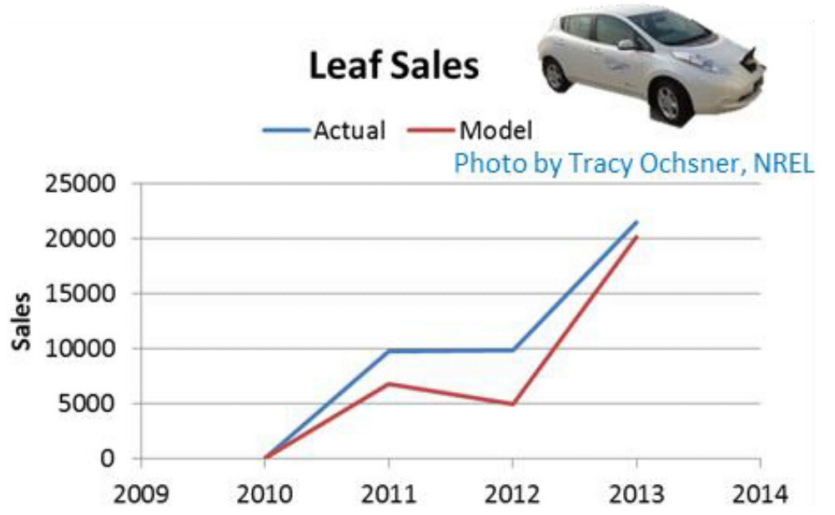

Figure 35. Sales validation for high-selling plug-in electric vehicle over time

\section{Interface}

ADOPT's GUI manages the inputs, simulation, results and validation. The interface consists of three figures. The primary figure lists the simulation options that have been defined, the time frame of the simulation, and a chart to view results, as seen in Figure 36.

Clicking the "New $\backslash$ Edit $\backslash$ View" button just above the simulation options box provides a second GUI for creating or modifying the scenario options to run, as seen in Figure 37. The input categories for each scenario are located on the left with their current choice in blue. A chart displaying the currently selected category and choice is on the top right, with buttons to add or delete options. The data are located in a table just below the chart where it can be modified.

New vehicles and their attributes can be added to the existing fleet database by selecting "Vehicle Data" in the Scenario/Region Category Combination menu in Figure 37. Then the data table loads with the current vehicle database and additional buttons. When the "New" button above the data table is selected, the current vehicle is copied with a specified name. The current data can then be modified to represent the attributes of the new vehicle.

A third interface manages and runs the validation. It provides the types of plots shown previously in the validation section, including time series validation and aggregate sales breakdowns for a given year. 
Simulation
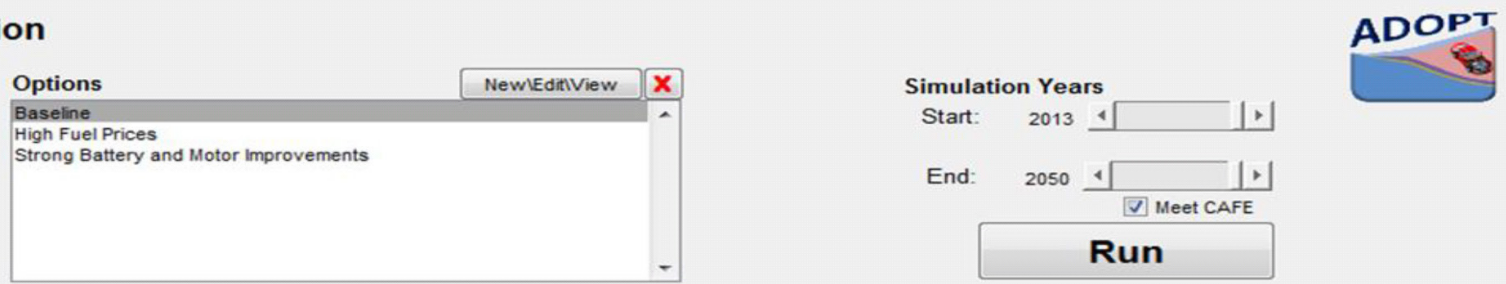

Results Notes:

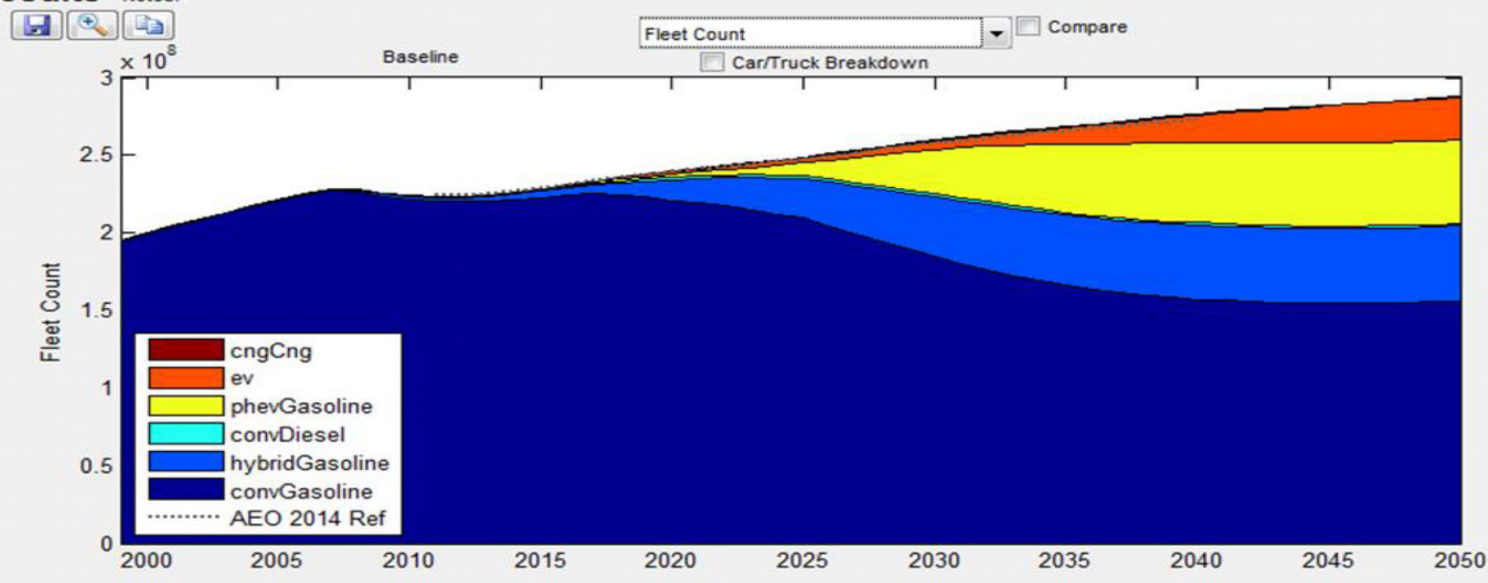

Figure 36. ADOPT's primary interface
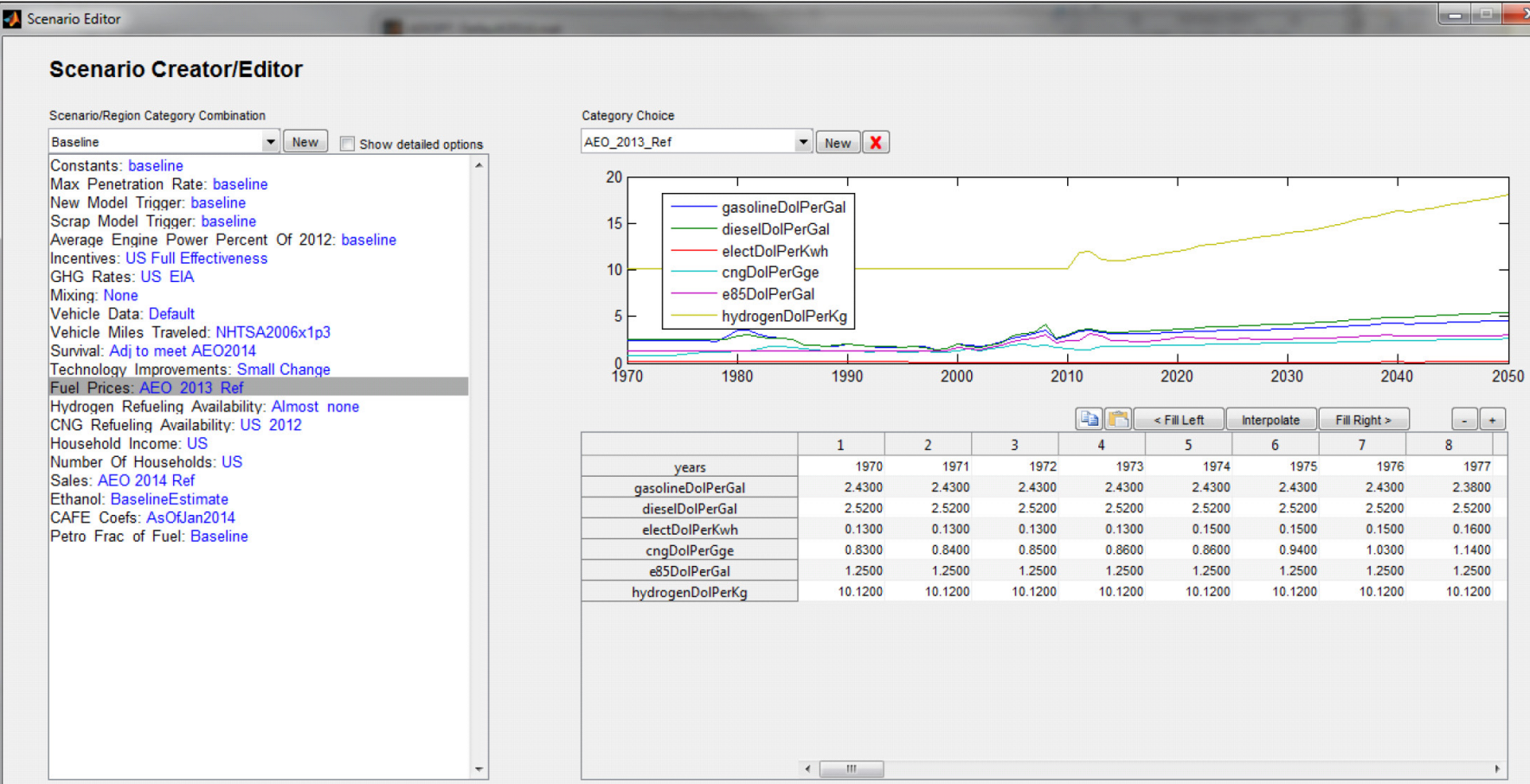

Figure 37. Scenario creator/editor interface

\section{Future Updates}

Several new updates are being integrated into ADOPT. Specific technology advances are being added as options for meeting CAFE regulations. Also, the data are being broken down into different regions to capture the variation in fuel prices and incomes, evaluate neighbor effects, and consider infrastructure rollout.

\section{Summary/Conclusions}

ADOPT is a light-duty vehicle consumer choice and stock model that estimates technology improvement impacts on U.S. light-duty vehicles sales, petroleum use, and GHG emissions. It uses a variation of the mixed multinomial logit method while enforcing CAFE regulations to estimate sales share of advanced vehicles along with all 
the existing light-duty vehicles. Its stock model captures key aspects, including VMT by age, new vehicle option introductions, and vehicle scrap rates by age. The results are extensively validated with historical sales to help ground future sales estimates in reality. The GUIs make it easy to use.

\section{References}

1. Berman, B., "The Risks of Using Hybrid Sales to Forecast Growth of Electric Cars," http://www.plugincars.com/risksusing-hybrid-sales-forecast-growth-electric-cars-128566.html, October 2013, retrieved October 2014.

2. Brooker, A., Gonder, J., Wang, L., Wood, E. et al., "FASTSim: A High Level Advanced Vehicle Powertrain, Cost, and Performance Comparison Tool," SAE Technical Paper 2015-010973, 2015, doi:10.4271/2015-01-0973.

3. Brooker, A., Ward, J., and Wang, L., "Lightweighting Impacts on Fuel Economy, Cost, and Component Losses," SAE Technical Paper 2013-01-0381, 2013, doi:10.4271/2013-01-0381.

4. “Annual Energy Outlook 2013,” U.S. Energy Information Administration, http://www.eia.gov/oiaf/aeo/tablebrowser/.

5. "Households by Total Money Income, Race, and Hispanic Origin of Householder," Historical Income Tables: Households, Table H-17, U.S. Census Bureau, https://www.census.gov/hhes/www/ income/data/historical/household/, retrieved October 2014.

6. Melaina, M., Bremson, J., and Solo, K. (2013). "Consumer Convenience and the Availability of Retail Stations as a Market Barrier for Alternative Fuel Vehicles," Preprint. 21 pp.; NREL Report No. CP-5600-56898. http://www.nrel.gov/docs/ fy13osti/56898.pdf

7. U.S. Environmental Protection Agency, Test Car List Data Files, http://www.epa.gov/otaq/tcldata.htm.

8. "The Ten Slowest Cars We Tested in 2010," Motor Trend (online). 2010. http://wot.motortrend.com/ten-slowest-carstested-2010-20289.html

9. "Top 10 Slowest 0-60 MPH Vehicles Motor Trend Tested in 2012," Motor Trend (online). 2012. http://wot.motortrend. com/top-10-slowest-0-60-mph-vehicles-motor-trend-testedin-2012-307101.html

10. "Best \& Worst Acceleration: These Vehicles Get up to Speed Quickly," Consumer Reports (online). October 2014. http:// consumerreports.org/cro/2012/05/best-worst-acceleration/index. $\underline{\mathrm{htm}}$

11. U.S. Department of Energy, Energy Efficiency and Renewable Energy, Alternative Fuels Data Center, http://www.afdc.energy. gov/data/search?q=hybrid+sales.
12. "www.fueleconomy.gov," U.S. Department of Energy, Office of Energy Efficiency and Renewable Energy. http://www. fueleconomy.gov/

13. "2017 and Later Model Year Light-Duty Vehicle Greenhouse Gas Emissions and Corporate Average Fuel Economy Standards; Final Rule," Title 49 Code of Federal Regulations Parts 523, 531, 533 et al. and 600, U.S. Environmental Protection Agency and Department of Transportation, National Highway Traffic Safety Administration: Washington, DC. October 15, 2012. Retrieved 2014-01-30.

14. Davis, S., Diegel, S., and Boundy, R., "Table 3.7" Transportation Energy Data Book, Edition 29, Oak Ridge National Laboratory: Oak Ridge, TN; 2010.

15. Davis, S., Diegel, S., and Boundy, R., "Table 3.12, Car Scrappage and Survival Rates, 1970, 1980 and 1990 Model Years," Transportation Energy Data Book, Edition 32, Oak Ridge National Laboratory: Oak Ridge, TN; page 3-16, 2013, http://info.ornl.gov/sites/publications/Files/Pub44660.pdf.

\section{Contact Information}

Aaron Brooker

Senior Research Engineer

National Renewable Energy Laboratory

Tel: 303-275-4392

Aaron.Brooker@nrel.gov

\section{Acknowledgments}

This work was supported by the U.S. Department of Energy's Vehicle Technologies Office. The authors would specifically like to thank Jacob Ward for his support.

\section{Definitions/Abbreviations}

ADOPT - Automotive Deployment Options Projection Tool

CAFE - Corporate Average Fuel Economy

CV - conventional vehicle

GHG - greenhouse gas

GUI - graphical user interface

HEV - hybrid electric vehicle

MPH - miles per hour

MSRP - manufacturer's suggested retail price

VMT - vehicle miles traveled per year

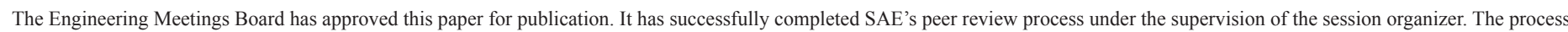
requires a minimum of three (3) reviews by industry experts.

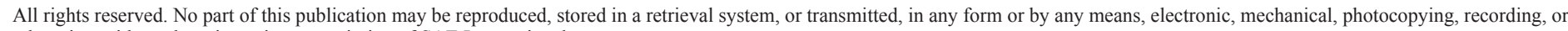
otherwise, without the prior written permission of SAE International.

Positions and opinions advanced in this paper are those of the author(s) and not necessarily those of SAE International. The author is solely responsible for the content of the paper.

ISSN 0148-7191

$\underline{\text { http://papers.sae.org/2015-01-0974 }}$ 